\title{
Conflicto armado en Colombia: aproximaciones desde la Revista Ocupación Humana, 1999 a 2019
}

\author{
Armed conflict in Colombia: Human Occupation Journal's \\ perspective from 1999 to 2019
}

Conflito armado na Colômbia: aproximações a partir da Revista Ocupação Humana, 1999 a 2019

\author{
Aleida Fernández Moreno ${ }^{1}$ \\ Recibido: 17 de febrero 2020 • Enviado para modificación: 3 de marzo 2020 • Aceptado: 16 de mayo 2020 \\ Fernández-Moreno, A. (2019). Conflicto armado en Colombia: aproximaciones desde la Revista Ocupación \\ Humana, 1999 a 2019. Revista Ocupación Humana, 19 (2), 8-24. https://doi.org/10.25214/25907816.833
}

\section{RESUMEN}

Con esta revisión se buscó evidenciar la presencia o ausencia del tema del conflicto armado en los textos publicados en la Revista Ocupación Humana y reconocer las aproximaciones al mismo desde la Terapia Ocupacional. Se realiza un análisis de las editoriales y los artículos relacionados con el conflicto armado colombiano publicados en esta revista en los últimos veinte años, teniendo en cuenta diferentes dimensiones que involucran el desplazamiento forzado, reinserción/reencuentro, resiliencia, trabajo comunitario, salud mental, entre otras. Se identifican nueve editoriales y cinco artículos relacionados con el tema. En varios de los textos se destaca el poder de la ocupación en la atención de personas y comunidades, y en escenarios diversos de actuación profesional. Estas experiencias, planteamientos y reflexiones constituyen propuestas para la paz.

\section{PALABRAS CLAVE}

conflicto armado, violencia, paz, desplazamiento de población, Terapia Ocupacional

\begin{abstract}
The presence or absence of the subject of armed conflict in Colombia, as well as its perspective from Occupational Therapy, was reviewed in the texts published by the Human Occupational Journal. An analysis of the editorials and articles related to the Colombian armed

${ }^{1}$ Terapeuta ocupacional. Magíster en Desarrollo Educativo y Social. Doctora en Ciencias Sociales. Profesora titular con tenencia de cargo, Universidad Nacional de Colombia. Bogotá, Colombia. cafernandezm@unal.edu.co. iD https://orcid.org/0000-0003-2937-9598
\end{abstract}


conflict published in this magazine in the last twenty years was carried out, considering dimensions of violence such as: forced displacement, reintegration / reunion, resilience, community work, mental health, among others. Nine editorials and five articles focused on the topic were identified. Several texts highlighted the power of occupation in the assistance to people and communities, in diverse professional scenarios. These experiences, approaches and reflections constitute proposals for peace.

\section{KEY WORDS}

armed conflicts, violence, peace, population displacement, Occupational Therapy

\section{RESUMO}

Esta revisão buscou evidenciar a presença ou ausência da questão do conflito armado nos textos publicados na Revista Ocupación Humana e reconhecer as aproximações, a partir da Terapia Ocupacional. Realizou-se uma análise dos editoriais e artigos relacionados ao conflito armado colombiano, publicados nesta revista nos últimos vinte anos, tendo em vista as diferentes dimensões que envolvem o deslocamento forçado: reinserção/reencontro; resiliência; trabalho comunitário; saúde mental; dentre outras. Identificaram-se nove editoriais e cinco artigos relacionados a este tema. Em vários dos textos, destacou-se o poder da ocupação na atenção de pessoas, comunidades e em diversos cenários de atuação profissional. Essas experiências, abordagens e reflexões constituem propostas pela paz.

\section{PALAVRAS-CHAVE}

conflito armado, violência, paz, deslocamento da população, Terapia Ocupacional

\section{Contexto histórico básico}

En clave histórica, es importante reconocer que una vez se logra la independencia de España en las tierras de Abya Yala ${ }^{2}$, región más conocida hoy en día como Latinoamérica, proliferaron guerras entre diferentes bandos hasta que dichos territorios lograron configurarse como naciones. Para Melo (2017), el surgimiento de Colombia como nación se alcanzó al superar conflictos bélicos de distinta índole, denominados genéricamente guerras civiles y desarrollados, particularmente, durante el siglo XIX e inicios del siglo XX; quizás la más conocida sea la Guerra de los Mil Días (1899-1902), que tuvo en Colombia y la actual Panamá grandes efectos sociales, económicos y políticos.

Si bien en muchos textos aún se habla de guerras civiles, en este artículo se acoge la denominación conflicto armado, dadas las características actuales del conflicto colombiano. Este:

Se define inicialmente como las acciones violentas desarrolladas entre las fuerzas armadas de un Estado reconocido y los grupos armados al margen de la ley o irregulares,

\footnotetext{
${ }^{2}$ Abya Yala con la conformación de la Coordinación Continental de las Nacionalidades y Pueblos Indígenas de Abya Yala. Vocablo de origen cuna (pueblo originario de la Sierra Nevada, al norte de Colombia, y habitante hoy de la costa panameña) que significa tierra madura, tierra viva o tierra que florece (Jaramillo, 2016).
} 
no gubernamentales, debidamente organizados; puede darse también entre dos grupos armados no gubernamentales; en los dos casos, operan bajo la dirección y aplicación de una jerarquía de mando, en un territorio sobre el cual de manera parcial o total ejercen control y realizan operaciones militares organizadas y frecuentes. (Cáceres, 2014, p.111)

Una versión del inicio del conflicto armado en el país la presenta el Centro de Memoria Histórica (Grupo de Memoria Histórica, 2013) en el informe ¡Basta ya! En este documento se señala que Colombia cuenta más de cincuenta años de conflicto armado y se ubica el comienzo de este en 1958, cuando la violencia bipartidista se transformó en subversiva. Sin embargo, es necesario advertir que no hay consenso sobre este origen, pues la violencia generada en las regiones a partir del asesinato del líder liberal Jorge Eliécer Gaitán, en 1948, fue excluida del informe.

A este respecto, Beltrán y Caruso alertan sobre la falta de precisión en la periodización del conflicto armado colombiano y hacen un Ilamado a "desprendernos de las narrativas oficiales del conflicto, [lo cual] exige ante todo reconocer los sesgos negacionistas ${ }^{3}$ de una periodización que ha ubicado los orígenes del mismo en los inicios del Frente Nacional y tomar distancia frente a una historiografía canónica" (2019, p.19).

Esto solo para denotar que, en Colombia, el reconocimiento y el estudio del conflicto armado son asuntos rela- tivamente recientes y enfrentan detractores y controversias. Estas cuestiones deben ser tenidas en cuenta en la historia del país, pues la violencia ha significado para muchas personas desplazamiento, desarraigo, incluso la muerte; han sido incontables las víctimas de violaciones, torturas, secuestros, entre otras muchas prácticas con las que se ha potenciado y degradado el conflicto durante años.

Es importante señalar la vigencia de los temas relacionados con el conflicto colombiano para la Terapia Ocupacional, en especial en el actual escenario que se deriva de la firma del Acuerdo de Paz con las Fuerzas Armadas Revolucionarias de Colombia - Ejército del Pueblo (FARC-EP) y los procesos que vive el país, como la convocatoria a la Comisión de la Verdad, la Jurisdicción Especial para la Paz (JEP), entre otras iniciativas que ofrecen un panorama complejo pero a la vez esperanzador respecto a la construcción de paz.

De otra parte, y dado que en Colombia se crea el primer programa de formación en Terapia ocupacional en el año 1966, Rodríguez et al. retoman a Mengo, quien señala que para ese entonces "se conformaron en Colombia los grupos guerrilleros Ejército de Liberación Nacional (ELN) y Fuerzas Armadas Revolucionarias de Colombia (FARC), ello como fruto de la exclusión social y política, la distribución desigual de las tierras y la injusticia social vividas hasta ese momento en el país" (2016, p.31-32). Así, en ese contexto en particular y teniendo en cuenta que

\footnotetext{
${ }^{3}$ Beltrán y Caruso (2019) se refieren como negacionista, en primer término, al historiador Darío Acevedo, nombrado en 2019 por el Gobierno Nacional como Director del Centro Nacional de Memoria Histórica. Además, aluden al negacionismo frente al genocidio de partidos políticos de oposición, como la Unión Patriótica.
} 
desde 1984 la publicación más importante para la profesión en el país ha sido la Revista Ocupación Humana, se pretende evidenciar si el conflicto ha sido reconocido o negado desde la Terapia Ocupacional y, más ampliamente, qué se sabe del tema a partir de editoriales y artículos publicados en esta Revista. Con estas preguntas, se inicia este artículo.

\section{Metodología}

Este artículo de revisión retoma metodológicamente los planteamientos de Vera, quien afirma que "es un tipo de artículo científico que, sin ser original, recopila la información más relevante de un tema específico" (2009, p.63). En este caso, con el propósito de hacer una aproximación a los temas que se han abordado en Terapia Ocupacional respecto al conflicto armado colombiano.

Como fuente primaria se contó con la Revista Ocupación Humana, tanto los artículos de diferente tipo como las editoriales publicadas entre 1999 y 2019, pues siendo la principal revista disciplinar en Terapia Ocupacional en el país, es un referente central de los desarrollos profesionales, académicos e investigativos gestados por la profesión. Según Ruano, las editoriales "se centran en nuevos hallazgos o descubrimientos, discuten sobre su validez científica, los ponen en contexto o especulan sobre sus posibles implicaciones" (2011, p.182). Por ello, y dado que estos textos suelen reflejar panorámicas profesionales amplias del contexto en el que se producen los artículos publicados en un número, se decidió incluirlas.
Inicialmente se pensó en abarcar la totalidad de volúmenes publicados durante la existencia de la Revista, es decir, desde 1984; no obstante, para el momento de esta revisión solo estaban disponibles en línea aquellos producidos a partir de 1999. Se fijó entonces la ventana de observación entre los años 1999 y 2019. Es necesario aclarar, además, que la publicación de la Revista estuvo suspendida entre el 2007 y el 2012, razón por la cual no se cuenta con artículos en ese periodo.

Para identificar los textos relacionados, se emplearon en primera instancia las palabras claves conflicto armado, desplazamiento, violencia, equidad, justicia y paz, en el buscador del sitio web de la Revista. De los artículos que arrojó esta búsqueda se revisaron el título y el resumen, o el texto completo en el caso de las editoriales; a partir de allí se seleccionaron aquellos que mostraban correspondencia con el tema y las palabras claves. Una vez ubicados, se analizó cómo desarrollaron estos temas y qué reflexiones plantearon al respecto; para los artículos se identificaron otras categorías de análisis que recogen sus principales aportes.

\section{Terapia Ocupacional y el conflicto colombiano}

En total se identificaron 14 textos a analizar, nueve editoriales y cinco artículos. En cuanto a las editoriales, en la tabla 1 se presentan sus aportes teniendo en cuenta lo que enuncian en relación con el conflicto armado colombiano y las reflexiones que sobre el tema realizan sus autoras. 
Tabla 1. Aportes de editoriales de la Revista Ocupación Humana al tema del conflicto armado colombiano y similares, 1999 a 2019.

\begin{tabular}{|c|c|c|}
\hline $\begin{array}{l}\text { Autoras/ Título/ } \\
\text { Ubicación }\end{array}$ & $\begin{array}{c}\text { Alusiones al conflicto armado, } \\
\text { violencia, paz }\end{array}$ & Otras reflexiones \\
\hline $\begin{array}{l}\text { Margarita González } \\
\text { Editorial } \\
\text { Vol. } 8 \text { (4), } 2000 .\end{array}$ & $\begin{array}{l}\text { “¿Cómo desconocer lo que nos está } \\
\text { pasando? Las personas con } \\
\text { discapacidad siguen aumentando en } \\
\text { nuestro país, las personas continúan sin } \\
\text { tener acceso a la educación, las } \\
\text { poblaciones especiales que por su } \\
\text { condición de vulnerabilidad requieren } \\
\text { de una discriminación positiva para su } \\
\text { integración social y laboral. (...) las } \\
\text { personas desplazadas por la violencia, } \\
\text { reinsertados, las mujeres cabeza de } \\
\text { familia de estratos bajos (cumplen el rol } \\
\text { de madre, cabeza de familia y } \\
\text { personas), niños víctimas de la } \\
\text { violencia (familiar y del conflicto } \\
\text { armado), los menores infractores y } \\
\text { contraventores, las personas de tercera } \\
\text { edad, los internos, los grupos étnicos, } \\
\text { los accidentes de trabajo y } \\
\text { enfermedades profesionales siguen } \\
\text { solicitando de unos programas muy } \\
\text { serios de prevención y educación, } \\
\text { atención y reubicación en el país." } \\
\text { (González, 2000, p.9) }\end{array}$ & $\begin{array}{l}\text { "... sea el ejemplo de haber estado informados de lo } \\
\text { que sucede y de prepararnos siempre para lograr plena } \\
\text { participación en los procesos de nuestro país." } \\
\text { (González, 2000, p.9) }\end{array}$ \\
\hline $\begin{array}{l}\text { Aida Navas } \\
\text { Discurso de } \\
\text { inauguración del XII } \\
\text { Congreso Colombiano } \\
\text { de Terapia } \\
\text { Ocupacional. Marzo } \\
\text { 9, } 10 \text { y } 11 \text { de } 2001 . \\
\text { Santa Marta. } \\
\text { Vol. } 9 \text { (1), } 2001 .\end{array}$ & $\begin{array}{l}\text { "Cuando siente uno el dolor de patria } \\
\text { estallar en el alma y no resiste un acto } \\
\text { más de desprecio por la vida (...). No } \\
\text { podemos seguir siendo ajenos a las } \\
\text { leyes que nos rigen, a los procesos que } \\
\text { se realizan en el país y que nos afectan } \\
\text { de una u otra forma." (Navas, 2001, } \\
\text { p.11) }\end{array}$ & $\begin{array}{l}\text { "La responsabilidad social nos exige protagonismo, } \\
\text { grandeza y trabajo colectivo para poder hacer lo que } \\
\text { espera de nosotros el país, nuestra gente y, con la } \\
\text { calidad que ellos lo merecen." "(..) cuando la realidad } \\
\text { nos muestra que más de la mitad de la población está } \\
\text { fuera o tiene grandes dificultades para acceder a nuestra } \\
\text { intervención y las opciones se ven cortadas por el } \\
\text { desempleo y la arbitrariedad. Cuando esto pasa, la } \\
\text { decisión que se tome puede ser, creo que debe ser, la } \\
\text { de formar parte de las decisiones, la de estar ahí para } \\
\text { ser consultado, para argumentar, para proponer, para } \\
\text { objetar, para ejecutar." (Navas, 2001, p.11) }\end{array}$ \\
\hline $\begin{array}{l}\text { Liliana Tenorio. } \\
\text { ¿Podemos ayudar a } \\
\text { construir un mundo } \\
\text { mejor? } \\
\text { Vol. } 11 \text { ( } 1 \text { y } 2 \text { ), } 2005 \text {. }\end{array}$ & Ninguna en particular. & $\begin{array}{l}\text { "Su papel [del terapeuta ocupacional] está en la } \\
\text { comprensión de esta realidad, que en lo inmediato es lo } \\
\text { cambiante y por tanto transformable, donde puede } \\
\text { hacer aportes importantes en cada servicio que preste; } \\
\text { realidad donde actúa como agente transformador en la } \\
\text { construcción de una sociedad más equitativa y justa." } \\
\text { (Tenorio, 2005, p.3) }\end{array}$ \\
\hline $\begin{array}{l}\text { Claudia Marcela Rozo } \\
\text { Reyes } \\
\text { Editorial } \\
\text { Vol. } 11 \text { (3 y 4), } 2006\end{array}$ & $\begin{array}{l}\text { "Identificar y perfilar el destino de } \\
\text { nuestro objeto de estudio exige el } \\
\text { reconocimiento de la importancia que } \\
\text { nuestro quehacer profesional tiene } \\
\text { dentro de un país con altos índices de } \\
\text { violencia, pobreza, desplazamiento, } \\
\text { condiciones de desigualdad." (Rozo, } \\
\text { 2006, p.1) }\end{array}$ & $\begin{array}{l}\text { "Un país inmerso en la violencia e injusticia exige } \\
\text { poner soluciones al alcance de la población que } \\
\text { articulen y totalicen la relación del hombre y el } \\
\text { entorno. La ocupación es sin duda el medio vinculante } \\
\text { más eficaz entre estos dos elementos." } \\
\text { "La ocupación, con su carácter multidimensional, } \\
\text { puede devolver y otorgar la dignidad personal, construir } \\
\text { sociedades más humanas, favorecer el sentido de } \\
\text { igualdad de oportunidades a los miembros de la } \\
\text { sociedad, superando todas las formas de discriminación } \\
\text { y alcanzando la participación social." (Rozo, 2006, p.1) }\end{array}$ \\
\hline
\end{tabular}




\begin{tabular}{|c|c|c|}
\hline $\begin{array}{l}\text { Autoras/ Título/ } \\
\text { Ubicación }\end{array}$ & $\begin{array}{c}\text { Alusiones al conflicto armado, } \\
\text { violencia, paz }\end{array}$ & Otras reflexiones \\
\hline $\begin{array}{l}\text { Aida Navas } \\
\text { Editorial } \\
\text { Vol. } 13 \text { (1), } 2013\end{array}$ & $\begin{array}{l}\text { "El maestro Guillermo Hoyos Vásquez } \\
\text { nos dejó las ideas básicas y poderosas } \\
\text { de "pensar bien" y "pensar en público", } \\
\text { en su convencimiento de que ese } \\
\text { esfuerzo por entender y abordar cada } \\
\text { uno desde sus competencias los } \\
\text { problemas del día a día, nos } \\
\text { compromete a ser responsables en el } \\
\text { pensar y nos exige involucrarnos en la } \\
\text { respuesta a los conflictos y las crisis del } \\
\text { país y del mundo." (Navas, 2013, p.3) }\end{array}$ & Ninguna en particular. \\
\hline $\begin{array}{l}\text { Consejo Directivo } \\
\text { Nacional, CCTO } \\
\text { Editorial } \\
\text { Vol. } 14 \text { (1), } 2014\end{array}$ & Ninguna en particular. & $\begin{array}{l}\text { "Creemos en una Terapia Ocupacional situada, crítica, } \\
\text { historizada, acorde a nuestras realidades del sur, tan } \\
\text { complejas como dinámicas. Consideramos prioritario } \\
\text { poner en acción nuestros legados originarios, en } \\
\text { particular aquellos que cuestionan nuestras formas } \\
\text { modernas e individuales de vivir y nos recuerdan que la } \\
\text { solidaridad, el trabajo colaborativo y la filiación } \\
\text { representan un modo Otro de constituirnos } \\
\text { comunitariamente." (Consejo Directivo Nacional } \\
\text { CCTO, 2014, p.3) }\end{array}$ \\
\hline $\begin{array}{l}\text { Lida Pérez, Liliana } \\
\text { Álvarez, Margarita } \\
\text { González y Aida } \\
\text { Navas } \\
\text { Editorial } \\
\text { Vol. } 15 \text { (2), } 2016\end{array}$ & $\begin{array}{l}\text { "La Terapia Ocupacional en Colombia } \\
\text { tiene matices únicos y una voz que hoy } \\
\text { hace eco en las reflexiones mundiales } \\
\text { sobre ocupación, participación y salud. } \\
\text { Nacida y moldeada bajo las presiones } \\
\text { propias de un país sumergido en } \\
\text { profundas inequidades sociales y } \\
\text { económicas, y en un conflicto armado } \\
\text { con raíces insondables, la concepción } \\
\text { de ocupación que hemos forjado como } \\
\text { profesión trasciende el quehacer } \\
\text { cotidiano y se mezcla con la identidad, } \\
\text { la dignidad y las dinámicas de poder, } \\
\text { saber y ser. Es esa concepción, esa voz } \\
\text { que emerge de una historia como } \\
\text { pocas, la que ha ganado fuerza en las } \\
\text { esferas internacionales y hoy se } \\
\text { posiciona como la esperanza de } \\
\text { profesionales que, como nosotros, } \\
\text { navegan en situaciones de conflicto, o } \\
\text { posacuerdo, y que también reconocen } \\
\text { las nuevas visiones y opciones de un } \\
\text { ser humano diverso." (Pérez et al., } \\
\text { 2016, p.3) }\end{array}$ & $\begin{array}{l}\text { "Les invitamos entonces a navegar por estas páginas, } \\
\text { conscientes del momento histórico: somos parte de una } \\
\text { profesión que de manera persistente ha generado } \\
\text { estrategias para que nuestro país sane, emerja; hemos } \\
\text { ayudado a formar ciudadanía (...) también a reflexionar } \\
\text { sobre la importancia de construir gremio, de unirnos, de } \\
\text { propulsar cambios y transformaciones de manera } \\
\text { colectiva." (Pérez et al., 2016, p.4) }\end{array}$ \\
\hline \multirow[b]{2}{*}{$\begin{array}{l}\text { Claudia Patricia Rojas } \\
\text { Castillo } \\
\text { Terapia Ocupacional } \\
\text { en el posacuerdo. } \\
\text { Retos para una } \\
\text { profesión que se } \\
\text { transforma. } \\
\text { Vol. } 17 \text { (1), } 2017\end{array}$} & \multicolumn{2}{|c|}{ Todo el texto aborda el tema, se destacan algunos apartes: } \\
\hline & $\begin{array}{l}\text { "Sin lugar a dudas, una de las } \\
\text { expresiones de la intensidad con que } \\
\text { vivimos este momento los colombianos } \\
\text { está atravesada por las emociones, } \\
\text { inquietudes, preguntas, convicciones } \\
\text { que nos genera la posibilidad de } \\
\text { implementar los Acuerdos de Paz } \\
\text { alcanzados entre el Gobierno Nacional } \\
\text { y la hoy Fuerza Alternativa } \\
\text { Revolucionaria del Común -FARC. Este } \\
\text { complejo escenario de posacuerdo } \\
\text { podemos verlo como una nueva puerta } \\
\text { de oportunidad para fortalecer nuestro } \\
\text { actuar profesional, pensado y } \\
\text { vinculado con los problemas sociales, } \\
\text { económicos y culturales que afectan a } \\
\text { grandes grupos humanos } \\
\text { históricamente excluidos en nuestro } \\
\text { país." (Rojas, 2017, p.3) }\end{array}$ & $\begin{array}{l}\text { "Revertir nuestras realidades marcadas por profundas } \\
\text { inequidades e injusticias sociales requiere que nos } \\
\text { hagamos cargo de nuestras posturas políticas y } \\
\text { atendamos de manera renovada y creativa los desafíos } \\
\text { que tenemos. (...) Las apuestas por la construcción de } \\
\text { vínculos a través de las acciones y ocupaciones } \\
\text { colectivas se vislumbran como una posibilidad real para } \\
\text { cimentar espacios sociales ligados a modos de vida que } \\
\text { protejan la vida y la salud." } \\
\text { "Otro asunto importante se relaciona con la atención } \\
\text { psicosocial, tanto a víctimas directas del conflicto como } \\
\text { a otras poblaciones que de alguna manera han } \\
\text { corporizado e incluido en sus imaginarios el miedo, la } \\
\text { desconfianza, la desesperanza como parte de sus } \\
\text { narrativas y pautas relacionales." } \\
\text { "Como terapeutas ocupacionales necesitamos ser } \\
\text { creativos para proponer mediaciones en las que las } \\
\text { narrativas ocupacionales, como experiencias de } \\
\text { reflexión-acción, tejan subjetividades y formas de hacer } \\
\text { atravesadas por la solidaridad y el bien común, } \\
\text { constituyéndose en hechos reales de reparación } \\
\text { integral, verdad y justicia social." (Rojas, 2017, p.5) }\end{array}$ \\
\hline
\end{tabular}




\begin{tabular}{|c|c|c|}
\hline $\begin{array}{l}\text { Autoras/ Título/ } \\
\text { Ubicación }\end{array}$ & $\begin{array}{l}\text { Alusiones al conflicto armado, } \\
\text { violencia, paz }\end{array}$ & Otras reflexiones \\
\hline $\begin{array}{l}\text { Liliana Álvarez } \\
\text { Jaramillo y Margarita } \\
\text { González } \\
\text { La ocupación como } \\
\text { derecho: reflexiones } \\
\text { del 33er Consejo y } 17^{\circ} \\
\text { Congreso Mundial de } \\
\text { la Federación Mundial } \\
\text { de Terapeutas } \\
\text { Ocupacionales. } \\
\text { Vol. } 18 \text { (1), } 2018 .\end{array}$ & $\begin{array}{l}\text { “(..) los países latinoamericanos se } \\
\text { caracterizan por la diversidad de sus } \\
\text { desarrollos culturales, sociales, } \\
\text { políticos y económicos, derivados, en } \\
\text { parte, de los grupos indígenas que } \\
\text { primero habitaron los diferentes } \\
\text { territorios y las reacciones ante las } \\
\text { prácticas colonizadoras del } \\
\text { descubrimiento. Sin embargo, este } \\
\text { colectivo se ha forjado con el tiempo } \\
\text { y como resultado no solo de que la } \\
\text { mayoría de los habitantes comparte el } \\
\text { idioma, sino de las luchas que han } \\
\text { caracterizado nuestras historias. } \\
\text { Colonización, dictaduras militares, } \\
\text { guerras, corrupción y pobreza, son } \\
\text { solo algunos de los flagelos que han } \\
\text { moldeado nuestras sociedades." } \\
\text { (Álvarez y González, 2018, p. 4) }\end{array}$ & $\begin{array}{l}\text { "Los terapeutas ocupacionales latinoamericanos, y en } \\
\text { nuestro caso los colombianos, tenemos pues un } \\
\text { compromiso urgente: el de ser activistas que habiten la } \\
\text { brecha y trabajen para cerrarla. Pero, ¿cómo lograr este } \\
\text { compromiso? ¿Qué acciones se requieren para lograr } \\
\text { cambios profundos y sociales desde la Terapia } \\
\text { Ocupacional?" (Álvarez y González, 2018, p.4) }\end{array}$ \\
\hline
\end{tabular}

Fuente: elaboración propia a partir de los textos citados.

Como puede observarse, la referencia al conflicto, el posacuerdo y la paz es una constante; esto se hace más evidente en el último lustro. Así mismo, se reconoce la actuación del terapeuta ocupacional en este escenario. Se encuentran editoriales sentipensantes, como la de Aida Navas, quien narra "el dolor de patria estallar en el alma y no resiste un acto más de desprecio por la vida" (2001, p.11).

En estos textos se asocian el origen de la profesión y el conflicto, varias detallan panorámicas de la situación nacional y las de los últimos cinco años, particularmente, abordan temas de paz y posacuerdo. Los orígenes de la profesión están marcados por el conflicto; así, según Pérez et al., la Terapia Ocupacional fue "nacida y moldeada bajo las presiones propias de un país sumergido en profundas inequidades sociales y económicas, y en un conflicto armado con raíces insondables" (2016, p.3). De otra parte, Álvarez y González (2018), en un contexto más amplio, señalan las guerras, la corrupción y la pobreza como flagelos para las sociedades latinoamericanas; mientras Rozo caracteriza a Colombia como "un país inmerso en la violencia e injusticia", "con altos índices de violencia, pobreza, desplazamiento, condiciones de desigualdad" (2006, p.1).

Varias editoriales se refieren a la responsabilidad social de la profesión; entre los grupos poblacionales que requieren la atención de terapeutas ocupacionales colombianos, González (2000) destaca a las personas desplazadas y a los niños víctimas de la violencia (familiar y del conflicto armado). Entre tanto, se sugieren las narrativas ocupacionales, las pautas relacionales y las prácticas de autocuidado y de cuidado del otro como aspectos a abordar. Cobra importancia la atención psicosocial, "tanto a víctimas directas del conflicto como a otras poblaciones (...) que de alguna manera han corporizado e incluido en sus imaginarios el miedo, la desconfianza, la desesperanza" (Rojas, 2017, p.4). 
Otras señalan el momento histórico: "somos parte de una profesión que de manera persistente ha generado estrategias para que nuestro país sane, emerja" (Pérez et al., 2016, p.2), y muestran, además, el complejo escenario del posacuerdo y sus implicaciones para una profesión como la Terapia Ocupacional (Rojas, 2017).

En clave de posacuerdo, Rojas destaca la posibilidad de vincularse al país, ella lo refiere como "oportunidad para fortalecer nuestro actuar profesional, pensado y vinculado con los problemas sociales, económicos y culturales que afectan a grandes grupos humanos históricamente excluidos en nuestro país" $(2017$, p.3). De igual manera, llama al uso de enfoques decoloniales e intersectoriales. En esta sintonía, en los últimos años aparece una nueva terminología donde se destaca la ocupación en clave de trabajo colectivo o ancestral (Pérez et al., 2016; Rojas, 2017).
Son varias las editoriales que convocan a las y los terapeutas ocupacionales a actuar como sujetos políticos y otras más a trabajar vía ocupacional por la dignidad, la equidad y la justicia social (Navas, 2001; Tenorio 2005; Rozo, 2006; Pérez et al., 2016; Rojas, 2017).

En cuanto a los cinco artículos analizados (tabla 2), tres de ellos se derivan de investigaciones realizadas como trabajos de grado en universidades públicas, dos de la carrera de Terapia Ocupacional de Universidad Nacional de Colombia, (Gómez y Torres, 1998; Cuellar, 1999) y uno de la Especialización en Desarrollo Humano de la Universidad Distrital (Albarracín y Contreras, 2016). Como se observa en las tablas 2 y 3, para aprovechar al máximo esta producción se amplió la matriz de captura de información.

Tabla 2. Terapia Ocupacional frente al conflicto armado colombiano, aportes de artículos publicados en la Revista Ocupación Humana, 1999 a 2019.

\begin{tabular}{|c|c|c|c|}
\hline $\begin{array}{c}\text { Autoras/ Título/ } \\
\text { Ubicación }\end{array}$ & $\begin{array}{l}\text { Concepciones sobre } \\
\text { conflicto armado, paz }\end{array}$ & Resultados, propuestas desde la Terapia Ocupacional & Principales recomendaciones \\
\hline $\begin{array}{l}\text { Marisol Gómez, Sara } \\
\text { Helena Torres y } \\
\text { María Teresa } \\
\text { Rodríguez. } \\
\text { Caracterización del } \\
\text { comportamiento } \\
\text { ocupacional de } \\
\text { personas } \\
\text { desplazadas por la } \\
\text { violencia }{ }^{4} \text {. } \\
\text { Vol. } 8(2), 1999 .\end{array}$ & $\begin{array}{l}\text { "La dinámica del } \\
\text { desplazamiento forzado ha } \\
\text { sido ampliamente estudiada } \\
\text { dentro de las áreas sociales } \\
\text { (...); sin embargo, desde la } \\
\text { perspectiva de la salud, no } \\
\text { existen estudios en esta } \\
\text { materia." (Gómez et al., } \\
\text { 1999, p.15) }\end{array}$ & $\begin{array}{l}\text { "...una primera caracterización de la población objeto en } \\
\text { cuanto a (...) procedencia, sexo, edad, escolaridad, } \\
\text { permanencia en Santa Fe de Bogotá y en el barrio Divino Niño, } \\
\text { responsables y motivos del desplazamiento, y deseo de } \\
\text { retorno." (Gómez et al., 1999, p.17) } \\
\text { "Como consecuencia del desplazamiento forzado, las personas } \\
\text { sufren cambios en sus estilos de vida en términos de } \\
\text { cotidianidad, puesto que se ven obligadas a cambiar de un } \\
\text { medio de vida generalmente rural a uno urbano con demandas } \\
\text { culturales, sociales, económicas y laborales diferentes a las } \\
\text { anteriores, lo que con lleva cambios abruptos en la ocupación } \\
\text { dentro de los procesos de trabajo tiempo y tiempo libre, y en las } \\
\text { expectativas de vida." (p.21) } \\
\text { "Se presentan cambios importantes en las ejecuciones } \\
\text { ocupacionales de tipo laboral, puesto que tradicionalmente las } \\
\text { personas desempeñaban labores propias del medio rural, } \\
\text { experimentando satisfacción por su productividad; mientras que } \\
\text { en el medio urbano las exigencias cambian, y por tanto las } \\
\text { nuevas ejecuciones ocupacionales laborales se circunscriben a } \\
\text { puestos de trabajo con demandas diferentes, y que por su } \\
\text { naturaleza son de baja remuneración." (p.23) } \\
\text { "El aprovechamiento del tiempo libre en el actual medio de } \\
\text { vida es mayor, puesto que la ciudad ofrece variedad de } \\
\text { opciones; mientras que en el medio anterior, la mayoría del } \\
\text { tiempo es dedicado a las actividades de tipo laboral y las } \\
\text { opciones de esparcimiento que ofrece este son limitadas." } \\
\text { (p.23) }\end{array}$ & $\begin{array}{l}\text { "Planear estrategias de acción para la } \\
\text { población desplazada, a través del } \\
\text { diseño, oferta e implementación de } \\
\text { programas de Terapia Ocupacional } \\
\text { dirigidos a promover un balance } \\
\text { ocupacional y a la adquisición de estilos } \\
\text { de vida saludables, dentro de un marco } \\
\text { de trabajo institucional." } \\
\text { "Involucrar la educación superior en la } \\
\text { temática del desplazamiento en términos } \\
\text { formativos, con el fin de sensibilizar al } \\
\text { recurso humano y de esta forma aportar } \\
\text { desde la perspectiva profesional, } \\
\text { soluciones de utilidad práctica a tal } \\
\text { fenómeno." } \\
\text { "Dar continuidad a la investigación } \\
\text { científica en temáticas sociales acordes } \\
\text { con la realidad del país, con el fin de } \\
\text { optimizar la atención a grupos } \\
\text { vulnerables, concatenando prácticas } \\
\text { profesionales con grupos } \\
\text { interdisciplinarios para abordajes con } \\
\text { mayor integralidad." (Gómez et al., } 1999 \text {, } \\
\text { p.26) }\end{array}$ \\
\hline
\end{tabular}

4 Investigación que obtuvo mención meritoria en la Universidad Nacional en 1998 y ocupó el primer lugar en el Concurso Mejores Trabajos de Grado de la misma Universidad (versión 1998-1999, área ciencias de la salud). Fue dirigida por la terapeuta ocupacional María Teresa Rodríguez (Q.E.P.D.). 


\begin{tabular}{|c|c|c|c|}
\hline $\begin{array}{l}\text { Autoras/ Título/ } \\
\text { Ubicación }\end{array}$ & $\begin{array}{l}\text { Concepciones sobre } \\
\text { conflicto armado, paz }\end{array}$ & Resultados, propuestas desde la Terapia Ocupacional & Principales recomendaciones \\
\hline $\begin{array}{l}\text { Patricia Cuellar } \\
\text { Sánchez. } \\
\text { Una propuesta de } \\
\text { atención sociolaboral } \\
\text { para exguerrilleros. } \\
\text { Vol. } 8 \text { (2) } 2000 \text { y } \\
\text { Vol. } 17 \text { (1) } 2017^{56} \text {. }\end{array}$ & \begin{tabular}{|l|} 
El artículo incorpora una \\
síntesis de las experiencias de \\
reinserción, a partir de \\
categorías internacionales, \\
políticas, sociales y militares. \\
En el informe de trabajo de \\
grado, Cuellar presenta en su \\
marco teórico: la violencia \\
en Colombia, los acuerdos de \\
paz y los programas \\
específicos para lograrla.
\end{tabular} & $\begin{array}{l}\text { "Allí, len la conversión ocupacional de los exguerrilleros } \\
\text { sandinistas en miembros de fuerzas armadas regulares y } \\
\text { funcionarios estatales o gubernamentales] la Terapia } \\
\text { Ocupacional cumplió un papel de agente dinamizador de los } \\
\text { procesos humanos y los procesos ocupacionales de los } \\
\text { exguerrilleros de base en un contexto de respeto y respaldo } \\
\text { social." (Cuellar, 2017, p. 90) } \\
\text { "(..) el análisis de la información reflejó un profundo impacto } \\
\text { en las áreas social y emocional, así como desajustes e } \\
\text { interrupciones en los procesos ocupacionales; el exguerrillero } \\
\text { debe reconstruir su proyecto de vida adaptándose a un medio } \\
\text { familiar, ocupacional y social abandonado al ingresar a la } \\
\text { organización armada, en medio de la desconfianza y el temor, } \\
\text { lo que evidencia la necesidad de una orientación terapéutica } \\
\text { para lograr la autovalorización de la historia ocupacional, como } \\
\text { punto de partida para afrontar de manera organizada, integrada, } \\
\text { productiva y realizante la transición ocupacional." (p.91) } \\
\text { "La experiencia comunitaria, la capacidad organizativa y de } \\
\text { liderazgo, los valores y hábitos adquiridos en la vida guerrillera, } \\
\text { aunados a la proyección de sus cualidades humanas y el } \\
\text { ascenso en el proceso realizante de su desempeño ocupacional } \\
\text { en la vida civil, pueden potenciarse con el programa Red de } \\
\text { Voluntades para el Reencuentro, para incidir positivamente en } \\
\text { los indicadores del país y en la consolidación de la paz." (p.93) } \\
\text { "La reconstrucción de la historia ocupacional que hace el } \\
\text { terapeuta ocupacional y el autorreconocimiento que de ella } \\
\text { haga el exguerrillero son herramientas básicas para la } \\
\text { valorización de la ocupación en sus diferentes etapas y facetas, } \\
\text { como un proceso productivo, conexo y continuo a través del } \\
\text { cual se desarrollan habilidades, se acumulan experiencias y se } \\
\text { adquieren conocimientos para alcanzar mayores niveles de } \\
\text { complejidad en el futuro desempeño ocupacional."(p.93-94) }\end{array}$ & $\begin{array}{l}\text { Para la Terapia Ocupacional: "Recopilar, } \\
\text { procesar y divulgar ante la comunidad } \\
\text { académica los postulados, principios, } \\
\text { hallazgos y experiencias del programa } \\
\text { Reorganización del Desempeño } \\
\text { Ocupacional, impulsar su desarrollo en el } \\
\text { campo sociolaboral por su carácter de } \\
\text { replicador que acumuló un destacado } \\
\text { reconocimiento social e institucional } \\
\text { mientras estuvo funcionando." (Cuellar, } \\
2017, \text { p.94) }\end{array}$ \\
\hline $\begin{array}{l}\text { Martha Tobón de } \\
\text { Awad. } \\
\text { Una postura ética } \\
\text { para la paz: más allá } \\
\text { del quehacer } \\
\text { profesional. } \\
\text { Vol. } 10 \text { (3 y } 4), \\
2004 .\end{array}$ & $\begin{array}{l}\text { "(...) me duelen los muertos y } \\
\text { los heridos del último acto } \\
\text { terrorista. Siento pena por los } \\
\text { secuestrados y sus familias. } \\
\text { Me cuesta trabajo creer que } \\
\text { alguien destroce el centro de } \\
\text { un pueblito que tanto costó } \\
\text { construir (...) Cómo ignoro a } \\
\text { una niña indefensa, violada y } \\
\text { embarazada. Tengo } \\
\text { vergüenza con esa familia } \\
\text { desplazada de algún pueblo } \\
\text { del Chocó, que pretende vivir } \\
\text { en esta fría ciudad. Cómo } \\
\text { voy a ignorar la muerte de } \\
\text { esos indigentes, hambrientos } \\
\text { fantasmas de la noche, } \\
\text { porque una bomba cayó } \\
\text { donde no tocaba..."(Tobón, } \\
\text { 2004, p.46) }\end{array}$ & $\begin{array}{l}\text { "(...) el devenir histórico de la profesión ha marcado también } \\
\text { un camino a seguir para el tratamiento de las disfunciones } \\
\text { psicosociales." (Tobón, 2004, p.50) } \\
\text { “(...) tanto la convivencia como la paz se encuentran } \\
\text { seriamente afectadas por el panorama de la Colombia de hoy. } \\
\text { Este es el medio de cultivo ideal para aumentar las } \\
\text { enfermedades que afectan la mente, el alma y, por lo tanto, el } \\
\text { desempeño ocupacional de las personas." (p.51) } \\
\text { "La propuesta que aquí se plantea se enmarca en la } \\
\text { Intervención comunitaria, uno de los campos de acción de } \\
\text { Terapia Ocupacional (Trujillo, 2002). Esta es la estrategia ideal } \\
\text { para atender comunidades en riesgo de disfunción psicosocial." } \\
\text { (p.51) } \\
\text { "Esta propuesta se centra en los niños, porque están expuestos a } \\
\text { la influencia de la situación nacional y de las acciones de las } \\
\text { personas con disfunciones psicosociales. Además, porque están } \\
\text { en plena formación de su personalidad, la cual puede ser } \\
\text { influenciada para promover una postura ética que contribuya a } \\
\text { lograr un cambio social para alcanzar la paz." (p.55) }\end{array}$ & $\begin{array}{l}\text { Se abstrae de los programas comunitarios } \\
\text { implementados por el jardín Infantil "es } \\
\text { su inmenso potencial de futuro, ya que es } \\
\text { absolutamente posible masificarlos a lo } \\
\text { largo y ancho del país." (Tobón, 2004, } \\
\text { p.58) } \\
\text { Que el programa se puede replicar en } \\
\text { otras regiones del país, "porque cuentan } \\
\text { con acciones prácticas y concretas, que } \\
\text { pueden utilizarse en cualquier contexto } \\
\text { con solo adaptar el lenguaje y las } \\
\text { actividades al medio sociocultural y } \\
\text { étnico de cada región." (p.58) }\end{array}$ \\
\hline $\begin{array}{l}\text { Luz Ángela } \\
\text { Albarracín Cerquera } \\
\text { y Karol Andrea } \\
\text { Contreras Torres. } \\
\text { La fuerza de las } \\
\text { mujeres: un estudio } \\
\text { de las estrategias de } \\
\text { resiliencia y la } \\
\text { transformación en la } \\
\text { ocupación humana } \\
\text { de mujeres víctimas } \\
\text { del conflicto armado } \\
\text { en Colombia'. } \\
\text { Vol. } 17 \text { (1), 2017. }\end{array}$ & $\begin{array}{l}\text { "Colombia, desde hace más } \\
\text { de } 50 \text { años, vive un continuo } \\
\text { de violencias sociopolíticas } \\
\text { que han afectado } \\
\text { directamente y de forma } \\
\text { diferencial a la población } \\
\text { civil, de acuerdo al nivel de } \\
\text { vulnerabilidad en que se } \\
\text { encuentren." (Albarracín y } \\
\text { Contreras, 2017, p.26). } \\
\text { "(...) se requiere conocer las } \\
\text { estrategias de resiliencia que } \\
\text { estas personas han } \\
\text { desarrollado frente a la } \\
\text { transformación de sus } \\
\text { actividades significativas ante } \\
\text { situaciones de adversidad, en } \\
\text { aras de aportar a la reparación } \\
\text { del tejido social." (p.26). }\end{array}$ & $\begin{array}{l}\text { "(...) fue evidente que las mujeres participantes han vivido } \\
\text { diferentes hechos victimizantes, no solo han sufrido el } \\
\text { desplazamiento, también delitos contra la integridad sexual, } \\
\text { torturas, amenazas, homicidios y desapariciones forzadas." } \\
\text { (Albarracín y Contreras, 2017, p.31). } \\
\text { "[Las participantes] reconocen que desde que los hechos adversos } \\
\text { ocurrieron, sus actividades significativas se han visto afectadas por } \\
\text { el desarraigo, la inseguridad, el temor por sus vidas, la ruptura de } \\
\text { vínculos afectivos, el castigo a la organización social y, en general, } \\
\text { el cambio de estatus de habitante de un territorio expulsor a } \\
\text { desplazada en la ciudad." (p.36). } \\
\text { "Las principales estrategias de resiliencia frente a la transformación } \\
\text { de actividades significativas en las mujeres participantes están } \\
\text { relacionadas con el hacer por sus vínculos y el autorreconocimiento } \\
\text { de capacidades y recursos propios para hacer frente a las } \\
\text { situaciones de adversidad." (p.36) }\end{array}$ & $\begin{array}{l}\text { "(...) realizar un abordaje con mayor } \\
\text { número de sesiones en las que se utilicen } \\
\text { elementos de danza que favorezcan un } \\
\text { espacio terapéutico y potencien el proceso } \\
\text { resiliente (...) indagar formas resilientes en } \\
\text { mujeres víctimas de hechos diferentes al } \\
\text { desplazamiento forzado que presentan una } \\
\text { alta prevalencia y pueden incidir de manera } \\
\text { significativa en la transformación de la } \\
\text { ocupación humana." (Albarracín y } \\
\text { Contreras, 2017, p.36). } \\
\text { "(...) indagar en las formas resilientes de } \\
\text { mujeres en los diferentes territorios de } \\
\text { acogida, ya que los aspectos culturales y las } \\
\text { políticas locales influyen en su proceso de } \\
\text { conformación." (p.37). }\end{array}$ \\
\hline
\end{tabular}

${ }^{5}$ Esta investigación se nutrió de las experiencias de paz vividas por su autora en Centroamérica, especialmente de Nicaragua, durante 14 años de ejercicio profesional (1980 a 1994). Fue dirigida por la terapeuta ocupacional Aleida Fernández Moreno.

${ }^{6}$ Nota de la Editora: este artículo fue publicado originalmente en la Revista Ocupación Humana en el año 2000. En 2017 se publicó nuevamente en la Revista, esta vez como documento histórico, teniendo en cuenta su relevancia para la profesión en dicho momento y que para entonces el original no estaba aún disponible en línea.

${ }^{7}$ Investigación desarrollada por una terapeuta ocupacional y una psicóloga, y dirigida por el Licenciado en Ciencias de la Educación Jorge David Sánchez. 


\begin{tabular}{|c|c|c|c|}
\hline $\begin{array}{l}\text { Autoras/ Título/ } \\
\text { Ubicación }\end{array}$ & $\begin{array}{l}\text { Concepciones sobre } \\
\text { conflicto armado, paz }\end{array}$ & Resultados, propuestas desde la Terapia Ocupacional & Principales recomendaciones \\
\hline $\begin{array}{l}\text { Adriana Caballero, } \\
\text { Aleida Fernández } \\
\text { Moreno, Solángel } \\
\text { García Ruíz, Aida } \\
\text { Navas y Maribel } \\
\text { Moreno Sosa. } \\
\text { Terapia Ocupacional } \\
\text { y desplazamiento } \\
\text { humano forzado. } \\
\text { Vol. 18 (1), } 2012 \\
(2018)^{8}\end{array}$ & $\begin{array}{l}\text { Las autoras presentan las } \\
\text { alarmantes cifras de } \\
\text { desplazmiento forzado en el } \\
\text { país. } \\
\text { "A partir de la Sentencia T- } \\
025 \text { de } 2004 \text {, se (...) constató } \\
\text { que la violación de derechos } \\
\text { humanos a la población en } \\
\text { desplazamiento había } \\
\text { ocurrido de manera masiva, } \\
\text { prolongada y reiterada, y que } \\
\text { no era imputable a una única } \\
\text { autoridad, sino que obedecía } \\
\text { a un problema estructural } \\
\text { que afectaba a toda la } \\
\text { política de atención diseñada } \\
\text { por el Estado, a partir de la } \\
\text { Ley } 387 \text { de 1997." (Caballero } \\
\text { et al., 2018, p. 66). }\end{array}$ & $\begin{array}{l}\text { Las autoras plantean inquietudes sobre la pertinencia de las } \\
\text { acciones desde Terapia Ocupacional para involucrar } \\
\text { ocupaciones dignas dentro de los proyectos de vida de las } \\
\text { personas que están reclamando procesos justos. } \\
\text { "En la reconstrucción de la memoria ocupacional que permita } \\
\text { recuperar las ocupaciones de las víctimas, aportando a la } \\
\text { contextualización de los procesos productivos para que } \\
\text { impacten positivamente y mantengan las tradiciones culturales } \\
\text { propias de las comunidades a las que se pertenece, según los } \\
\text { roles que desempeñan o desempeñaron y sus edades; aspectos } \\
\text { estos fundamentales para el fortalecimiento de lazos y la } \\
\text { identificación de recursos propios que contribuyan en la } \\
\text { comunidad receptora." (Caballero et al., 2018, p.68). } \\
\text { "Si bien el componente productivo es vital, pensar en el papel } \\
\text { que el ocio juega en el fortalecimiento de lazos sociales abre } \\
\text { campos complementarios desde lo psicosocial para estos } \\
\text { procesos, al ser un medio cotidiano que se puede utilizar para } \\
\text { el fortalecimiento de la confianza, de las rutinas y del } \\
\text { afianzamiento de prácticas culturales propias." (p. 69). } \\
\text { "(...) la Terapia ocupacional, en materia de programas de } \\
\text { capacitación laboral y de generación de ingresos, debe tener un } \\
\text { papel importante referido a la provisión de servicios dirigidos a } \\
\text { la orientación ocupacional de los sujetos, entendiendo que } \\
\text { dicha orientación tiene por objetivo promover la autonomía, } \\
\text { socialización, productividad y realización personal, a través de } \\
\text { la evaluación de las capacidades, intereses y formación } \\
\text { adquirida por el individuo, para identificar el perfil ocupacional } \\
\text { hacia la escogencia de los programas de formación laboral." } \\
\text { (p.69). }\end{array}$ & $\begin{array}{l}\text { "Para la atención a la niñez y la juventud, } \\
\text { la Terapia Ocupacional cuenta con las } \\
\text { competencias del saber necesarias para } \\
\text { generar propuestas que contrarresten las } \\
\text { causas principales de la deserción escolar } \\
\text { por parte de la población desplazada en } \\
\text { los entornos receptores, tales como la } \\
\text { explotación laboral, los impactos físicos y } \\
\text { psicológicos derivados del evento mismo } \\
\text { del desplazamiento, el maltrato y la } \\
\text { discriminación en el ámbito escolar, el } \\
\text { bajo rendimiento académico y las altas } \\
\text { tasas de repitencia, la alta incidencia de } \\
\text { casos de extraedad sin el } \\
\text { acompañamiento requerido y los altos } \\
\text { patrones de embarazo adolescente." } \\
\text { (Caballero et al., 2018, p.69). }\end{array}$ \\
\hline
\end{tabular}

Fuente: elaboración propia a partir de los textos citados.

Frente al conflicto armado colombiano, Tobón (2004) inicia su artículo con una sentida narración de su cotidianidad frente a esta realidad $y$, a partir de allí, presenta su programa psicosocial para la construcción de paz. En otros artículos, se define directamente el tema central, bien sea el desplazamiento forzado (Gómez, Torres y Rodríguez, 1999) o la reinserción (Cuellar, 2000/2017), sin presentar mayor contexto sobre el conflicto armado colombiano y sus implicaciones, quizás suponiendo que el común de la población colombiana lo tiene claro. Un panorama del conflicto más amplio, que incluye lo normativo, lo ofrecen Albarracín y Contreras (2017), quienes además definen y categorizan la resiliencia como su eje temático. De manera similar, el texto de Caballero et al. (2018) sobre el desplazamiento forzado presenta estadísticas, datos y cifras al 2012, con un contexto ampliado de normatividad vigente (ver tabla 3 ).
Las propuestas de programas desde Terapia Ocupacional incorporan experiencias con personas y comunidades desplazadas por la violencia (Gómez et al., 1999; Caballero et al., 2018), con mujeres que despliegan resiliencia (Albarracín y Contreras, 2017) o para grupos de exguerrilleros (Cuellar 2000, 2017), todas ellas dirigidas a viabilizar la paz. Las propuestas, se anuncia o se extrapola, pueden ser desarrolladas en las diferentes regiones de Colombia (Cuellar 2000/2017; Tobón, 2004). También hay un Ilamado constante sobre temas de salud mental o atención psicosocial que puede desarrollar la profesión (Gómez et al., 1999; Tobón, 2004; Albarracín y Contreras, 2017; Caballero et al., 2018), tal como lo destacan en sus editoriales Tenorio (2005) y Tobón (2006).

Vale la pena destacar las potentes contribuciones de los artículos deriva-

${ }^{8}$ Texto elaborado desde el Colegio Colombiano de Terapia Ocupacional en el año 2012 y publicado como documento histórico en el Volumen 18 № 1 de 2018 de la Revista Ocupación Humana. 
dos de investigaciones, pues sus autoras trabajan directamente con la población afectada por el conflicto (Gómez et al., 1999; Albarracín y Contreras, 2016), lo que les permite acercarse a temas como el ocio y el uso del tiempo libre, por ejemplo, que aparece como favorable al llegar a las ciudades; o el acceso a servicios de salud, restringido en las zonas rurales de procedencia.

Así mismo, Cuellar (2000/2017) recupera la experiencia y la trayectoria profesional de más de 14 años en $\mathrm{Ni}$ caragua, con una visión que interpela la llamada reinserción, propuesta por el gobierno de la época, y propone el reencuentro como figura que reconoce el lugar político y los aportes de los exguerrilleros a los procesos de paz que se pactaban en el gobierno del presidente Andrés Pastrana (1998-2002), particularmente.

Las investigaciones que derivaron en estos artículos contaron con modelos teóricos de respaldo, como el Modelo de la Ocupación Humana (Gómez et al., 1999), el Desempeño Ocupacional Realizante (Cuellar, 2000/2017) y el Marco de Trabajo en Terapia Ocupacional (Albarracín y Contreras, 2016). Por su parte, la propuesta de Tobón (2004) combinó marcos de referencia de la Ocupación Humana (Boulding, Bruner, Reilly, Kielhofner, Burke) y el Comportamiento Ocupacional (Reilly, Michelman, Shannon y Takata), entre otros (ver tabla 3). Lo anterior revela las posibilidades de la profesión para participar en temas relacionados con el conflicto armado y con la actual etapa de posacuerdo, en síntesis, en los procesos de paz que se vienen gestando en las distintas regiones, como ya lo habían denotado en sus editoriales Pérez et al. (2016) y Rojas (2018).

De otro lado, Caballero et al. (2018) plantean la memoria ocupacional para recuperar las ocupaciones de las víctimas de la violencia, especialmente aquellas desplazadas; además de lo productivo, destacan el poder curativo del ocio, como previamente lo habían señalado Gómez et al. (1999). En esta misma clave, Gómez et al. (1999), Caballero et al. (2012/2018) y Albarracín y Contreras (2017) plantean la transformación de las actividades significativas que tuvieron los colectivos desplazados y de mujeres.

La clave cultural de las ocupaciones está presente como demandas y condiciones en los planteamientos de Gómez et al. (1999) y en la propuesta de Cuellar (2000/2017). También Tobón (2004) advierte sobre la pertinencia de tener en cuenta el origen cultural y étnico, así como el nexo de lo cultural con lo espiritual. En Albarracín y Contreras (2017), a través de la danza, y en Caballero et al. (2018), mediante la recuperación de aspectos culturales y el afianzamiento de prácticas culturales propias de quienes han enfrentado el desplazamiento forzado.

Por último, la clave de género también está presente en estos artículos, al reconocer los efectos particulares del conflicto para mujeres y niñas (Tobón, 2004; Albarracín y Contreras, 2017; Caballero et al., 2018). A su vez, Tobón (2004) y Caballero et al. (2018) Ilaman la atención hacia la infancia y la juventud como poblaciones particularmente vulneradas en el marco del conflicto colombiano. 
Tabla 3. Normativa y referencias clave en artículos relacionados con el conflicto colombiano publicados en la Revista Ocupación Humana entre 1999 y 2019.

\begin{tabular}{|c|c|c|}
\hline Artículo & $\begin{array}{l}\text { Normativa } \\
\text { considerada }\end{array}$ & Referencias clave \\
\hline $\begin{array}{l}\text { Caracterización del } \\
\text { comportamiento } \\
\text { ocupacional de personas } \\
\text { desplazadas por la } \\
\text { violencia (Gómez et al., } \\
\text { 1999). }\end{array}$ & Ley 387 de 1997. & $\begin{array}{l}\text { Caicedo Concha, M.E. (1997). El Terapeuta ocupacional y } \\
\text { la rehabilitación en salud mental. Revista Ocupación } \\
\text { Humana, 7(1), 13-20. } \\
\text { Rodríguez, M.T. (1989). Competencias ocupacionales y } \\
\text { desarrollo comunitario: un modelo operativo. Revista } \\
\text { Ocupación Humana, } 3 \text { (1), 45-55. }\end{array}$ \\
\hline $\begin{array}{l}\text { Una propuesta de } \\
\text { atención sociolaboral } \\
\text { para exguerrilleros } \\
\text { (Cuellar, 2000/2017). }\end{array}$ & No registra. & $\begin{array}{l}\text { Cuéllar, P. (1999). De la reinserción al reencuentro: una } \\
\text { mirada desde la Terapia Ocupacional. (Trabajo de } \\
\text { grado de pregrado). Universidad Nacional de Colombia. } \\
\text { Torres, M. (1996). Programa Reorganización del } \\
\text { Desempeño Ocupacional. Universidad Nacional de } \\
\text { Colombia (inédito). } \\
\text { Trujillo, A. (1995). Desempeño ocupacional realizante: un } \\
\text { modelo sobre los propósitos de la Terapia Ocupacional. } \\
\text { Revista Ocupación Humana, } 6 \text { (2), 11-21. }\end{array}$ \\
\hline $\begin{array}{l}\text { Una postura ética para la } \\
\text { paz: más allá del } \\
\text { quehacer profesional } \\
\text { (Tobón, 2004). }\end{array}$ & No registra. & $\begin{array}{l}\text { Santacruz, M.L. (2002). La dimensión espiritual en Terapia } \\
\text { Ocupacional. Revista Ocupación Humana, 9(4), 52-60. } \\
\text { Trujillo, A. (2002). Terapia Ocupacional. Conocimiento y } \\
\text { práctica en Colombia. Universidad Nacional de } \\
\text { Colombia. } \\
\text { La autora además retoma autores como Kielhofner (1992), } \\
\text { Chen et al. (1996), Neuhaus (1997), Spencer et al. } \\
\text { (1997) Van Amburg (1997), Howard y Howard (1997), } \\
\text { quienes han hecho énfasis en la necesidad de incluir la } \\
\text { esfera espiritual y ética en el tratamiento. }\end{array}$ \\
\hline $\begin{array}{l}\text { La fuerza de las mujeres: } \\
\text { un estudio de las } \\
\text { estrategias de resiliencia } \\
\text { y la transformación en la } \\
\text { ocupación humana de } \\
\text { mujeres víctimas del } \\
\text { conflicto armado en } \\
\text { Colombia. (Albarracín y } \\
\text { Contreras, 2017). }\end{array}$ & $\begin{array}{l}\text { Ley } 1257 \text { de } \\
2008 . \\
\text { Auto } 092 \text { de } 2008, \\
\text { Corte } \\
\text { Constitucional. } \\
\text { Ley } 1448 \text { de } \\
2011 .\end{array}$ & $\begin{array}{l}\text { American Occupational Therapy Association -AOTA. } \\
\text { (2008). Marco de Trabajo para la Práctica de Terapia } \\
\text { Ocupacional: Dominio y Proceso (2da ed.). } \\
\text { Grupo de Investigación Ocupación y Realización Humana. } \\
\text { (2011). Ocupación: sentido, realización y libertad. } \\
\text { Diálogos ocupacionales en torno al sujeto, la sociedad y } \\
\text { el medio ambiente. Universidad Nacional de Colombia. }\end{array}$ \\
\hline $\begin{array}{l}\text { Terapia Ocupacional y } \\
\text { desplazamiento humano } \\
\text { forzado (Caballero et. al., } \\
\text { 2012/2018). }\end{array}$ & $\begin{array}{l}\text { Ley } 387 \text { de } 1997 . \\
\text { Sentencia T-025 } \\
\text { de } 2004 \text {, Corte } \\
\text { Constitucional. }\end{array}$ & $\begin{array}{l}\text { Moreno, M. (2010). Contribución de terapia ocupacional en } \\
\text { los procesos de reparación al proyecto de vida de las } \\
\text { víctimas del conflicto armado bajo el enfoque de ASD } \\
\text { (Trabajo de grado de especialización). Universidad } \\
\text { Nacional de Colombia. } \\
\text { Caballero, A. (2011). La infantilización de la niñez en } \\
\text { desplazamiento y su derecho a la reparación integral } \\
\text { (Tesis de maestria). Universidad Nacional de Colombia. }\end{array}$ \\
\hline
\end{tabular}

Fuente: elaboración propia a partir de los textos citados.

\section{Conclusiones}

Existe un reconocimiento del conflicto armado colombiano en la Terapia Ocupacional, expresado tanto en las editoriales como en varios artículos publicados en la Revista Ocupación Humana. En los textos revisados se evidencian las acciones desarrolladas y el potencial de la Terapia Ocupacional para hacer frente a problemáticas derivadas del conflicto en Colombia, tales como el desplazamiento forzado, la reinserción o, mejor, el reencuentro. 
Tanto las editoriales como los artículos despliegan la clave ocupacional como recuperar el tejido social, propiciar la resiliencia y, en últimas, construir paz; destacan actividades significativas, laborales, culturales y de ocio, en el marco de ocupaciones dignas para las distintas poblaciones, entre las que se destacan mujeres, niños, niñas, jóvenes y exguerrilleros.

Este artículo no ha pretendido ser exhaustivo y debe ser considerado bajo esa limitante, pues varios artículos fueron excluidos a partir de las palabras claves seleccionadas; aun así, es claro que existen algunos que indirectamente han considerado el conflicto en Colombia. Por ejemplo, Caicedo Concha expone en su texto sobre rehabilitación en salud mental que "además de la necesaria intervención de los terapeutas en los programas de salud mental, se hace cada vez más necesario que participen en los programas contra la violencia a todos los niveles, en los de las víctimas de la violencia colectiva como campos de desplazados, hogares sustitutos, programas de bienestar, lugares de reclusión, indigentes y otros" (1997, p.19). En otros artículos de la Re-

\section{Referencias}

Albarracín, L. A. y Contreras, K. A. (2016). La fuerza de las mujeres: un estudio de las estrategias de resiliencia y la transformación en la ocupación humana de mujeres víctimas del conflicto armado en Colombia. (Trabajo de grado de Especialización, Universidad Distrital Francisco José de Caldas). Repositorio Institucional UDistrital. http://repository.udistrital. edu.co/bitstream/11349/2657/1/Albarrac\%C3\%ADnCerqueraLuzAngela2016.pdf vista también se encuentran menciones al conflicto como contexto histórico, por ejemplo, Rodríguez et al. (2016). Por ello, se deben revisar aquellos que enuncien temas históricos de la Terapia Ocupacional, proyección o perspectivas de la profesión y, en particular, las publicaciones relacionadas con temas comunitarios o de salud mental.

Considerar la producción investigativa de las universidades formadoras de terapeutas ocupacionales sería relevante, pues este tema también registra un significativo incremento, particularmente en la última década; los semilleros de investigación y los trabajos de grado pueden ser fuente de nuevas publicaciones. En ese sentido, una consulta preliminar a las directivas de los programas de formación en Terapia Ocupacional del país, realizada en el marco de la elaboración de este texto, permitió dar cuenta de una interesante producción de trabajos de grado e investigaciones, además de algunos artículos ya publicados (ver anexo). También se reportaron prácticas, ponencias y semilleros, que no se amplían en este artículo.

Albarracín, L.A. y Contreras, K.A. (2017). La fuerza de las mujeres: un estudio de las estrategias de resiliencia y la transformación en la ocupación humana de mujeres víctimas del conflicto armado en Colombia. Revista Ocupación Humana, 17(1), 25-38. https://doi.org/10.25214/25907816.154

Álvarez, L.y González, M. (2018). La ocupación como derecho: reflexiones del 33er Consejo y $17^{\circ}$ Congreso Mundial de la Federación Mundial de Terapeutas Ocupacionales. 
Revista Ocupación Humana, 18(1), 3-6. https://doi.org/10.25214/25907816.192

Beltrán, M.A. y Caruso L.N. (2019). Negacionismo del conflicto colombiano. Revista CEPA, 3(28).

Caballero, A., Fernández, A., García, S., Navas, A. y Moreno, M. (2018). Terapia Ocupacional y desplazamiento humano forzado. Colombia, febrero de 2012. Revista Ocupación Humana, 18(1), 65-70. https://doi. org/10.25214/25907816.195

Cáceres, L. G. (2014). Categorización de las confrontaciones armadas desde el Derecho Internacional Humanitario (DIH). Verba luris, (32), 105-120. https://doi.org/10.18041/0121-3474/verbaiuris. 32.40

Caicedo Concha, M.E. (1997). El Terapeuta Ocupacional y la rehabilitación en salud mental. Revista Ocupación Humana, 7 (1), 13-20.

Consejo Directivo Nacional, Colegio Colombiano de Terapia Ocupacional (2014). Editorial. Revista Ocupación Humana, 14(1), 3-4. https://doi. org/10.25214/25907816.75

Cuéllar, P. (1999). De la reinserción al reencuentro: una mirada desde la Terapia Ocupacional. (Trabajo de grado de pregrado, Universidad Nacional de Colombia).

Cuéllar, P. (2000). Una propuesta de atención sociolaboral para ex guerrilleros. Revista Ocupación Humana, 8(3), 24-32. https:// doi.org/10.25214/25907816.511

Cuéllar, P. (2017). Una propuesta de atención sociolaboral para exguerrilleros. Revista Ocupación Humana, 17(1), 89-95. https://doi.org/10.25214/25907816.158
Gómez, M. y Torres, S.E. (1998). Caracterización del comportamiento ocupacional de personas desplazadas por la violencia. (Trabajo de grado de pregrado, Universidad Nacional de Colombia).

Gómez, M., Torres, S. E. y Rodríguez, M. T. (1999). Caracterización del comportamiento ocupacional de personas desplazadas por la violencia. Revista Ocupación Humana, 8(2), 13-31. https://doi. org/10.25214/25907816.483

González, M. (2000). Editorial. Revista Ocupación Humana, 8(4), 9. https://doi. org/10.25214/25907816.516

Grupo de Memoria Histórica (2013). ¡Basta ya! Colombia: Memorias de guerra y dignidad. Centro de Memoria Histórica.

Jaramillo, A. (2016). Atlas histórico de América Latina y el Caribe. Aportes para la para la descolonización cultural y pedagógica. Centro de Estudios de Integración Latinoamericana Manuel Ugarte. Universidad Nacional de Lanús. http://atlaslatinoamericano.unla.edu.ar/index.php

Melo, J. O. (2017). Historia mínima de Colombia. La historia de un país que ha oscilado entre la guerra y la paz, la pobreza y el bienestar, el autoritarismo y la democracia.Turner.

Navas, A. (2001). Discurso de inauguración XII Congreso Colombiano de Terapia Ocupacional. Marzo 9, 10 y 11 de 2001. Santa Marta. Revista Ocupación Humana, 9(1), 9-11. https://doi. org/10.25214/25907816.523

Navas, A. (2013). Editorial. Revista Ocupación Humana, 13(1), 3-4. https://doi. org/10.25214/25907816.6 
Pérez, L., Álvarez, L., González, M. y Navas, A. (2016). Editorial. Revista Ocupación Humana, 15(2), 3-4. https://doi. org/10.25214/25907816.24

Rodríguez, L., Camargo, N., \& Escobar, X. (2016). Terapia Ocupacional: una perspectiva histórica desde la Universidad Nacional de Colombia (1966-1989). Revista Ocupación Humana, 16(2), 26-45. https://doi.org/10.25214/25907816.132

Rojas, C. P. (2017). Terapia Ocupacional en el posacuerdo. Retos para una profesión que se transforma. Editorial. Revista Ocupación Humana, 17(1), 3-6. https://doi. org/10.25214/25907816.150

Rozo, C. M. (2006). Editorial. Revista Ocupación Humana, 11(3 y 4), 1-3. https://doi. org/10.25214/25907816.79
Ruano, A. (2011). Una nota editorial sobre los editoriales de Gaceta Sanitaria. Gaceta Sanitaria, 25(3), 182-183.

Tenorio, L. (2005). ¿Podemos ayudar a construir un mundo mejor? Revista Ocupación Humana, 11(1 y 2), 1-3. https://doi. org/10.25214/25907816.214

Tobón, M. (2004). Una postura ética para la paz: más allá del quehacer profesional. Revista Ocupación Humana, 10 (3 y 4), 43-60. https://doi.org/10.25214/25907816.213.

Vera, O. (2009). Cómo escribir artículos de revisión. Revista Médica La Paz, 15(1), 63-69 
Anexo. Investigaciones sobre el conflicto armado colombiano en programas de formación en Terapia Ocupacional en Colombia.

\begin{tabular}{|c|c|c|c|c|}
\hline Tipo & Año & Título & Autores/as & Ubicación \\
\hline Proyecto & 2018 & $\begin{array}{l}\text { La ocupación humana como constructora de justicia social en el } \\
\text { proceso de paz en Colombia }\end{array}$ & $\begin{array}{l}\text { Yury Arenis Olarte } \\
\text { María Elizabeth Fonseca }\end{array}$ & \\
\hline $\begin{array}{l}\text { Capítulo de } \\
\text { Libro }\end{array}$ & 2020 & $\begin{array}{l}\text { Identidades y retos ocupacionales para la construcción de paz en } \\
\text { Colombia en el marco de la justicia social. }\end{array}$ & $\begin{array}{l}\text { Yury Arenis Olarte } \\
\text { María Elizabeth Fonseca }\end{array}$ & $\begin{array}{l}\text { En: La paz en crisis: } \\
\text { conflictos y actores } \\
\text { heredados, emergentes y } \\
\text { transformados en } \\
\text { Colombia (en prensa). }\end{array}$ \\
\hline \multicolumn{5}{|c|}{ Universidad Manuela Beltrán } \\
\hline \multirow{9}{*}{$\begin{array}{l}\frac{0}{0} \\
\frac{\pi}{60} \\
0 \\
0 \\
0 \\
\frac{0}{\pi} \\
\frac{\pi}{2} \\
\frac{\pi}{2}\end{array}$} & 2017 & $\begin{array}{l}\text { Intervención de terapia ocupacional con personas víctimas del } \\
\text { conflicto armado en Colombia. }\end{array}$ & $\begin{array}{l}\text { Yessica Jhoana Herrera } \\
\text { Paola Alejandra Velandia }\end{array}$ & \multirow[t]{9}{*}{ Biblioteca } \\
\hline & 2017 & $\begin{array}{l}\text { Terapia ocupacional en el acompañamiento psicosocial a los } \\
\text { procesos de duelo por desplazamiento forzado. }\end{array}$ & María Camila Molina & \\
\hline & 2018 & $\begin{array}{l}\text { Desempeño ocupacional y proceso de inclusión educativa de } \\
\text { niños de } 7 \text { a } 11 \text { años víctimas de desplazamiento forzado en } \\
\text { Colombia. }\end{array}$ & $\begin{array}{l}\text { Gabriela Palomino } \\
\text { Yuri Milena Valero }\end{array}$ & \\
\hline & 2018 & $\begin{array}{l}\text { Sistematización de experiencias de acompañamiento psicosocial } \\
\text { en niños y niñas víctimas del conflicto armado. }\end{array}$ & $\begin{array}{l}\text { Karen Viviana Fierro } \\
\text { Laura Daniela Plazas }\end{array}$ & \\
\hline & 2019 & $\begin{array}{l}\text { Niñez y conflicto armado: análisis en torno a las áreas de la } \\
\text { ocupación. }\end{array}$ & $\begin{array}{l}\text { Aura Johanna Rojas } \\
\text { María Mónica Muñoz }\end{array}$ & \\
\hline & 2019 & $\begin{array}{l}\text { Narrativas de las experiencias ocupacionales en personas víctimas } \\
\text { del desplazamiento forzado antes, durante y después del hecho } \\
\text { victimizante. }\end{array}$ & $\begin{array}{l}\text { Andrea del Pilar González } \\
\text { Julieth Andrea Rojas }\end{array}$ & \\
\hline & 2019 & $\begin{array}{l}\text { Sentidos y significados que guían las elecciones ocupacionales de } \\
\text { los niños, niñas y jóvenes desvinculados del conflicto armado en } \\
\text { Colombia }\end{array}$ & $\begin{array}{l}\text { Martha Liliana Cerón } \\
\text { Katherine Andrea Lozano }\end{array}$ & \\
\hline & 2020 & $\begin{array}{l}\text { Participación de terapia ocupacional en procesos de inclusión } \\
\text { laboral en personas reincorporadas del conflicto armado en } \\
\text { Colombia. }\end{array}$ & $\begin{array}{l}\text { Enna Julieth Sánchez } \\
\text { Gloria Patricia Vera }\end{array}$ & \\
\hline & 2020 & $\begin{array}{l}\text { Exploración de sentidos y significados del arte como ocupación } \\
\text { en mujeres que vivieron el conflicto armado colombiano. }\end{array}$ & $\begin{array}{l}\text { Carolina Jara } \\
\text { Sandy Paola muñoz }\end{array}$ & \\
\hline \multicolumn{5}{|c|}{ Universidad de Pamplona } \\
\hline Tipo & Año & Título & Autores/as & Ubicación \\
\hline \multirow[t]{3}{*}{$\begin{array}{l}\text { Trabajos } \\
\text { de grado }\end{array}$} & 2012 & $\begin{array}{l}\text { Influencia del estrés postraumático en la salud mental del contexto } \\
\text { social de la población en situación de desplazamiento. }\end{array}$ & $\begin{array}{l}\text { María José Aramendiz } \\
\text { Belquis Xiomara Vega }\end{array}$ & \multirow[t]{3}{*}{ Biblioteca } \\
\hline & 2016 & $\begin{array}{l}\text { Transculturización y su influencia en la ejecución en las } \\
\text { Actividades de la Vida Diaria (AVD) en mujeres desplazadas del } \\
\text { municipio de Pamplona. }\end{array}$ & Joyle Sharim Rojas & \\
\hline & 2016 & $\begin{array}{l}\text { Función ocupacional y ambiente en mujeres cabeza de familia } \\
\text { víctimas del desplazamiento forzado. }\end{array}$ & Claudia Patricia Villamizar & \\
\hline \multicolumn{5}{|c|}{ Universidad de Santander - UDES Bucaramanga } \\
\hline $\begin{array}{l}\text { Trabajo } \\
\text { de grado }\end{array}$ & 2018 & $\begin{array}{l}\text { Caracterización de habilidades productivas en personas } \\
\text { desmovilizadas pertenecientes a la Agencia para la } \\
\text { Reincorporación y la Normalización de la ciudad de Bucaramanga. }\end{array}$ & $\begin{array}{l}\text { Esther Julieth Cárcamo } \\
\text { Deisy Juliana Carreño }\end{array}$ & Sin reporte. \\
\hline \multicolumn{5}{|c|}{ Universidad del Rosario } \\
\hline $\begin{array}{l}\text { Trabajo } \\
\text { de grado } \\
\text { (pasantía) }\end{array}$ & 2012 & $\begin{array}{l}\text { Participación social en niños y niñas de } 0 \text { a } 5 \text { años en situación de } \\
\text { desplazamiento en la localidad de Kennedy, Fundación Dorcas. }\end{array}$ & $\begin{array}{l}\text { Elvis Siprian Castro } \\
\text { María Helena Restrepo } \\
\text { Viviana Andrea López } \\
\text { Jennifer Seidner Torres }\end{array}$ & $\begin{array}{l}\text { http://www.innovacesal. } \\
\text { org/innova_system/app/ } \\
\text { webroot/archivos/privad } \\
\text { a/foropadre/110/archivo } \\
\text { s/Documento_Part_Soci } \\
\text { al_Foro_Innova_Definiti } \\
\text { vo_.doc }\end{array}$ \\
\hline $\begin{array}{l}\text { Trabajo } \\
\text { de grado }\end{array}$ & 2015 & $\begin{array}{l}\text { Oportunidades de participación laboral en la localidad de Bosa } \\
\text { para jóvenes entre los } 18 \text { y } 24 \text { años desplazados por el conflicto } \\
\text { armado. }\end{array}$ & Janneth Fernanda de la Cruz & $\begin{array}{l}\text { Repositorio Universidad } \\
\text { del Rosario }\end{array}$ \\
\hline Proyecto & 2014 & $\begin{array}{l}\text { Project in the Dorcas Foundation. Occupational therapy and } \\
\text { displacement, an approximation in the early childhood: experiences } \\
\text { in the Dorcas Foundation. }\end{array}$ & $\begin{array}{l}\text { Kelsey Waisanen } \\
\text { Elvis Siprian Castro }\end{array}$ & $\begin{array}{l}\text { En: Occupational } \\
\text { therapy and its } \\
\text { relevance in social } \\
\text { projects. Relationships, } \\
\text { learning and } \\
\text { opportunities: Collection } \\
\text { of experiences of } \\
\text { University of Alberta } \\
\text { MSc OT students in } \\
\text { Bogotá (pp.21-27). } \\
\text { Repositorio Universidad } \\
\text { del Rosario. }\end{array}$ \\
\hline Libro & 2015 & $\begin{array}{l}\text { Estrategias de enseñanza aprendizaje en ambientes musicales: } \\
\text { enfoque para niños, niñas y adolescentes con discapacidad víctimas } \\
\text { del conflicto armado colombiano. }\end{array}$ & $\begin{array}{l}\text { Óscar Javier Larrota } \\
\text { Elvis Siprian Castro } \\
\text { Karen Aguía Rojas } \\
\text { María Carolina Navas } \\
\text { Mónica María Ruiz }\end{array}$ & $\begin{array}{l}\text { Libro publicado por la } \\
\text { Universidad del Rosario. }\end{array}$ \\
\hline
\end{tabular}




\begin{tabular}{|c|c|c|c|c|}
\hline \multicolumn{5}{|c|}{ Universidad del Valle } \\
\hline Tipo & Año & Título & Autores/as & Ubicación \\
\hline \multirow[t]{5}{*}{$\begin{array}{l}\text { Trabajos } \\
\text { de grado }\end{array}$} & 2001 & $\begin{array}{l}\text { Caracterización del impacto del fenómeno de desplazamiento en } \\
\text { los integrantes de la Asociación de Desplazados "El Retorno" del } \\
\text { municipio de Jamundi, de acuerdo al subsistema de habituación del } \\
\text { Modelo de la Ocupación Humana y la Teoría del Rol. }\end{array}$ & $\begin{array}{l}\text { María Isabel Hurtado } \\
\text { Andrés Mauricio Lemos }\end{array}$ & \multirow[t]{5}{*}{$\begin{array}{l}\text { Biblioteca Mario } \\
\text { Carvajal } \\
\text { Sede San Fernando }\end{array}$} \\
\hline & 2001 & $\begin{array}{l}\text { Diseño de una propuesta de intervención para niños y niñas } \\
\text { desplazados de sus hogares de origen por problemas de violencia. }\end{array}$ & $\begin{array}{l}\text { Carmen Leonora Acevedo } \\
\text { Paola Andrea Chaverra }\end{array}$ & \\
\hline & 2003 & $\begin{array}{l}\text { Caracterización del rol laboral de la población afectada por el } \\
\text { desplazamiento forzado que llegan al municipio de Tuluá. }\end{array}$ & $\begin{array}{l}\text { María Del Pilar Delgado } \\
\text { Eliana María Ospina } \\
\text { Julián Andrés Santa }\end{array}$ & \\
\hline & 2008 & $\begin{array}{l}\text { Descripción del desempeño ocupacional en el rol de jugador de } \\
\text { niños desplazados entre los } 7 \text { y } 10 \text { años de edad. }\end{array}$ & $\begin{array}{l}\text { Mayda Alejandra Molina } \\
\text { Sara Ruiz } \\
\text { Diana Lucía Vélez } \\
\text { Francisco José Vivas } \\
\text { Lina Paola Viveros }\end{array}$ & \\
\hline & 2009 & $\begin{array}{l}\text { Perfil de funcionamiento y discapacidad en victimas por minas anti- } \\
\text { personas para ayudar el proceso de habilitación - rehabilitación en } \\
\text { terapia ocupacional en un centro asistencial en salud de alta } \\
\text { complejidad en la ciudad de Cali. }\end{array}$ & $\begin{array}{l}\text { Alejandra María Marmolejo } \\
\text { Diana Esperanza Perdomo } \\
\text { Vanessa Téllez Ortiz }\end{array}$ & \\
\hline $\begin{array}{l}\text { Proyecto } \\
\text { en curso }\end{array}$ & 2020 & $\begin{array}{l}\text { El proceso de habituación en exguerrilleros FARC EP en proceso de } \\
\text { reincorporación entre } 2017 \text { y } 2020 \text {. Estudios de caso. }\end{array}$ & $\begin{array}{l}\text { Ángela Eliana Bastidas } \\
\text { Alexandra Cifuentes } \\
\text { Dana Vanessa Herrera }\end{array}$ & $\begin{array}{l}\text { Informes: Escuela de } \\
\text { Rehabilitación. } \\
\text { Profesora Melania } \\
\text { Satizabal }\end{array}$ \\
\hline Artículo & 2019 & $\begin{array}{l}\text { El movimiento indígena como víctima del conflicto armado en } \\
\text { Colombia y su apuesta por una paz desde una visión territorial. }\end{array}$ & $\begin{array}{l}\text { Carlos Alberto Osorio } \\
\text { Melania Satizabal }\end{array}$ & $\begin{array}{l}\text { Revista Hallazgos. } \\
\text { https://doi.org/10.15332/ } \\
2422409 \times .4369\end{array}$ \\
\hline \multicolumn{5}{|c|}{ Universidad Nacional de Colombia } \\
\hline & Año & Título & Autores/as & Ubicación \\
\hline \multirow{11}{*}{ 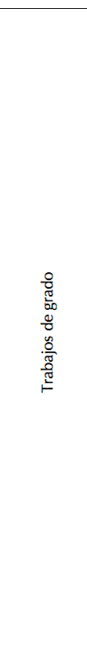 } & 1998 & $\begin{array}{l}\text { Caracterización del comportamiento ocupacional de personas desplazadas } \\
\text { por la violencia. }\end{array}$ & $\begin{array}{l}\text { Marisol Gómez } \\
\text { Sara Elena Torres Mogollón }\end{array}$ & \multirow[t]{11}{*}{$\begin{array}{l}\text { Centro de documentación } \\
\text { programa de Terapia } \\
\text { Ocupacional }\end{array}$} \\
\hline & 1999 & De la reinserción al reencuentro: una mirada desde la terapia ocupacional. & Patricia Cuellar Sánchez & \\
\hline & 2004 & $\begin{array}{l}\text { Propuesta de un programa de orientación y adaptación ocupacional para } \\
\text { adolescentes en situación de desvinculación del conflicto armado. }\end{array}$ & $\begin{array}{l}\text { Miledy Aydee Carreño } \\
\text { Adriana Carolina Pachón } \\
\text { Carolina Soto }\end{array}$ & \\
\hline & 2004 & $\begin{array}{l}\text { Impacto de la violencia en la salud y desempeño ocupacional de la } \\
\text { población colombiana. }\end{array}$ & $\begin{array}{l}\text { Robinson Coy } \\
\text { Diego Raúl Martínez }\end{array}$ & \\
\hline & 2006 & $\begin{array}{l}\text { Diseño de una plataforma comunicativa para población desplazada: una } \\
\text { mirada desde terapia ocupacional. }\end{array}$ & $\begin{array}{l}\text { Olga Lucia Bermúdez } \\
\text { Carol Viviana Rodríguez } \\
\text { Paola Andrea Rodríguez }\end{array}$ & \\
\hline & 2010 & $\begin{array}{l}\text { Cómo el terapeuta ocupacional utiliza la expresión artística como medio } \\
\text { de intervención para lograr la reparación emocional y adaptación social de } \\
\text { niños y niñas de } 7 \text { a } 13 \text { años de edad en situación de desplazamiento con } \\
\text { discapacidad (cognitiva- sensorial- mental- física). }\end{array}$ & $\begin{array}{l}\text { Angélica Alarcón } \\
\text { Miriam Amaya Quintero } \\
\text { Cindy Viasus Wilches }\end{array}$ & \\
\hline & 2014 & $\begin{array}{l}\text { Prácticas culturales y ocupaciones de la comunidad Wounaan Nonam, una } \\
\text { visión desde terapia ocupacional. }\end{array}$ & $\begin{array}{l}\text { Francy Yineth Caballero } \\
\text { Angélica María Marciales } \\
\text { Ruby Haide Perilla } \\
\text { Manuel Yoryino Tobar } \\
\end{array}$ & \\
\hline & 2017 & $\begin{array}{l}\text { Reconociendo las ocupaciones colectivas como aporte para la paz: diálogo } \\
\text { de saberes y haceres con comunidades del pacífico colombiano. }\end{array}$ & $\begin{array}{l}\text { Kelly Tatiana Cetina } \\
\text { Carlos Julio Rivera } \\
\text { Paula Andrea Rodríguez }\end{array}$ & \\
\hline & 2017 & $\begin{array}{l}\text { Rescate de ocupaciones insurgentes. Narrativas ocupacionales de } \\
\text { guerrilleros en proceso de reincorporación que aportan a la construcción } \\
\text { de paz. }\end{array}$ & Victoria Cotamo & \\
\hline & 2017 & $\begin{array}{l}\text { Ocupación y corporalidades: transformaciones con la comunidad indígena } \\
\text { Kankuama. }\end{array}$ & $\begin{array}{l}\text { Mónica Alejandra Bermúdez } \\
\text { Edith Natalia Gutiérrez } \\
\text { Jeimmy Katherine Ramírez }\end{array}$ & \\
\hline & 2019 & $\begin{array}{l}\text { Terapia Ocupacional en salud pública rural. Aportes desde una experiencia } \\
\text { en la Macarena-Meta. }\end{array}$ & $\begin{array}{l}\text { Danny Gisseth Herrera } \\
\text { Lady Dayana Ramos } \\
\text { Paula Andrea Sánchez }\end{array}$ & \\
\hline \multirow{3}{*}{$\frac{0}{\frac{0}{3}}$} & 2015 & $\begin{array}{l}\text { Participación de terapia ocupacional en contextos de conflicto armado y } \\
\text { postconflicto. }\end{array}$ & $\begin{array}{l}\text { Olga Luz Peñas } \\
\text { Ana María Gómez } \\
\text { Eliana Isabel Parra }\end{array}$ & \begin{tabular}{|l|} 
Revista Salud Pública. \\
https://doi.org/10.15446/rsap.v \\
17 n4.53047 \\
\end{tabular} \\
\hline & 2016 & $\begin{array}{l}\text { Terapia ocupacional en la normatividad colombiana relacionada con } \\
\text { conflicto armado. }\end{array}$ & $\begin{array}{l}\text { Olga Luz Peñas } \\
\text { Ana María Gómez } \\
\text { Eliana Isabel Parra } \\
\text { Carlos Julio Rivera } \\
\text { Clara Marcela Ovalle }\end{array}$ & $\begin{array}{l}\text { Revista de la Facultad de } \\
\text { Medicina. } \\
\text { https://doi.org/10.15446/revfac } \\
\text { med.v64n4.53446 }\end{array}$ \\
\hline & 2017 & $\begin{array}{l}\text { Experiencias de terapia ocupacional para la paz: aportes desde las regiones } \\
\text { colombianas. }\end{array}$ & $\begin{array}{l}\text { Ana María Gómez } \\
\text { Olga Luz Peñas } \\
\text { Eliana Isabel Parra }\end{array}$ & $\begin{array}{l}\text { Revista de Salud Pública. } \\
\text { https://doi.org/10.15446/rsap.v } \\
\text { 19n5.62482 } \\
\end{array}$ \\
\hline
\end{tabular}

Fuente: elaboración propia a partir de la información reportada por algunos de los programas de formación en Terapia Ocupacional en Colombia. 